\title{
МЕТОД ПРОГНОЗА ДЕФОРМАЦИИ ЗЕМНОЙ ПОВЕРХНОСТИ ПРИ УСТРОЙСТВЕ КОТЛОВАНОВ В УСЛОВИЯХ ПЛОТНОЙ ГОРОДСКОЙ ЗАСТРОЙКИ С ПРИМЕНЕНИЕМ СПОСОБА «СТЕНА В ГРУНТЕ»
}

\author{
П.А.ДЕМЕНКОВ, Л.А.ГОЛДОБИНА, О.В.ТРУШКО \\ Санкт-Петербургский горный университет, Санкт-Петербург, Россия
}

\begin{abstract}
В статье предложен метод прогноза деформации земной поверхности при устройстве котлованов в условиях плотной городской застройки с применением способа «стена в грунте», основанный на моделировании методом конечных элементов.

Приведены результаты численного моделирования строительства полузаглубленного сооружения под защитой «стены в грунте». Выявлены закономерности изменения напряженно-деформированного состояния в зависимости от параметров стены и физико-механических свойств грунтов. В работе приведены мульды оседаний поверхности при строительстве котлована способом «стена в грунте», эпюры изгибающих моментов, поперечных и продольных сил, возникающих в стене.

Для оценки расхождения результатов моделирования в плоской и объемной постановке задачи выполнены численные эксперименты в Plaxis 2D и 3D.

Ключевые слова: котлованы; оседания; стена в грунте; смещения; грунты; полузаглубленные подземные сооружения; метод конечных элементов
\end{abstract}

Как цитировать эту статью: Деменков П.А. Метод прогноза деформации земной поверхности при устройстве котлованов в условиях плотной городской застройки с применением способа «стена в грунте» / П.А.Деменков, Л.А.Голдобина, О.В.Трушко // Записки Горного института. 2018. Т. 233. С. 480-486. DOI: 10.31897/PMI.2018.5.480

Введение. Уменьшение свободной наземной территории для застройки и развития транспортной инфраструктуры, инженерных систем и обеспечения местами парковки личного автотранспорта требуют в мегаполисах и крупных города все более активного использования подземного пространства, что приводит к необходимости устройства глубоких котлованов и строительства полузаглубленных сооружений в условиях плотной застройки. Освоение подземного пространства городов осуществляется как открытым, так и закрытым способом [2, 12].

Интенсивное освоение подземного пространства городов в условиях плотной городской застройки может оказывать негативное воздействие на нее [3, 4, 6-9,13]. Для снижения негативного влияния при строительстве полузаглубленных сооружений на основание и фундаменты соседних зданий наиболее эффективным является «стена в грунте», которая позволяет минимизировать воздействие на окружающую застройку $[1,5,6]$.

Анализируя результаты работ $[5,11]$, посвященных расчету и натурным наблюдениям за строительством глубоких котлованов, можно выделить следующие факторы, оказывающие наибольшее влияние на формирование напряженно-деформированного состояния ограждающих конструкций и вмещающего массива: инженерно-геологические условия строительства, глубина сооружения и жесткость ограждающих конструкций.

Метод прогноза деформации земной поверхности при устройстве котлованов. Деформации грунтового массива в окрестности полузаглубленного сооружения могут вызвать повреждения зданий и сооружений, расположенных в зоне влияния. Прогноз перемещений грунтового массива при строительстве полузаглубленных подземных сооружений способом «стена в грунте» в условиях плотной городской застройки является важной и сложной задачей.

Наиболее полную картину деформирования грунтового массива при сооружении полузаглубленного сооружения можно получить при использовании численных методов анализа. Алгоритм расчета полузаглубленных подземных сооружений представлен на рис.1.

В первую очередь при подготовке исходных данных задаются характеристики грунтового массива. Особую осторожность необходимо проявлять при оценке результатов инженерногеологических изысканий, так как часто лабораторные испытания не проводятся, а характеристики грунтов принимаются по нормативным документам, но даже при проведении лабораторных испытаний их результаты могут существенно отличаться от реальных характеристик грунтов. Это связано прежде всего с влиянием строительных работ на гидрогеологическую ситуацию строительной площадки и ее окрестности и масштабным эффектом. 


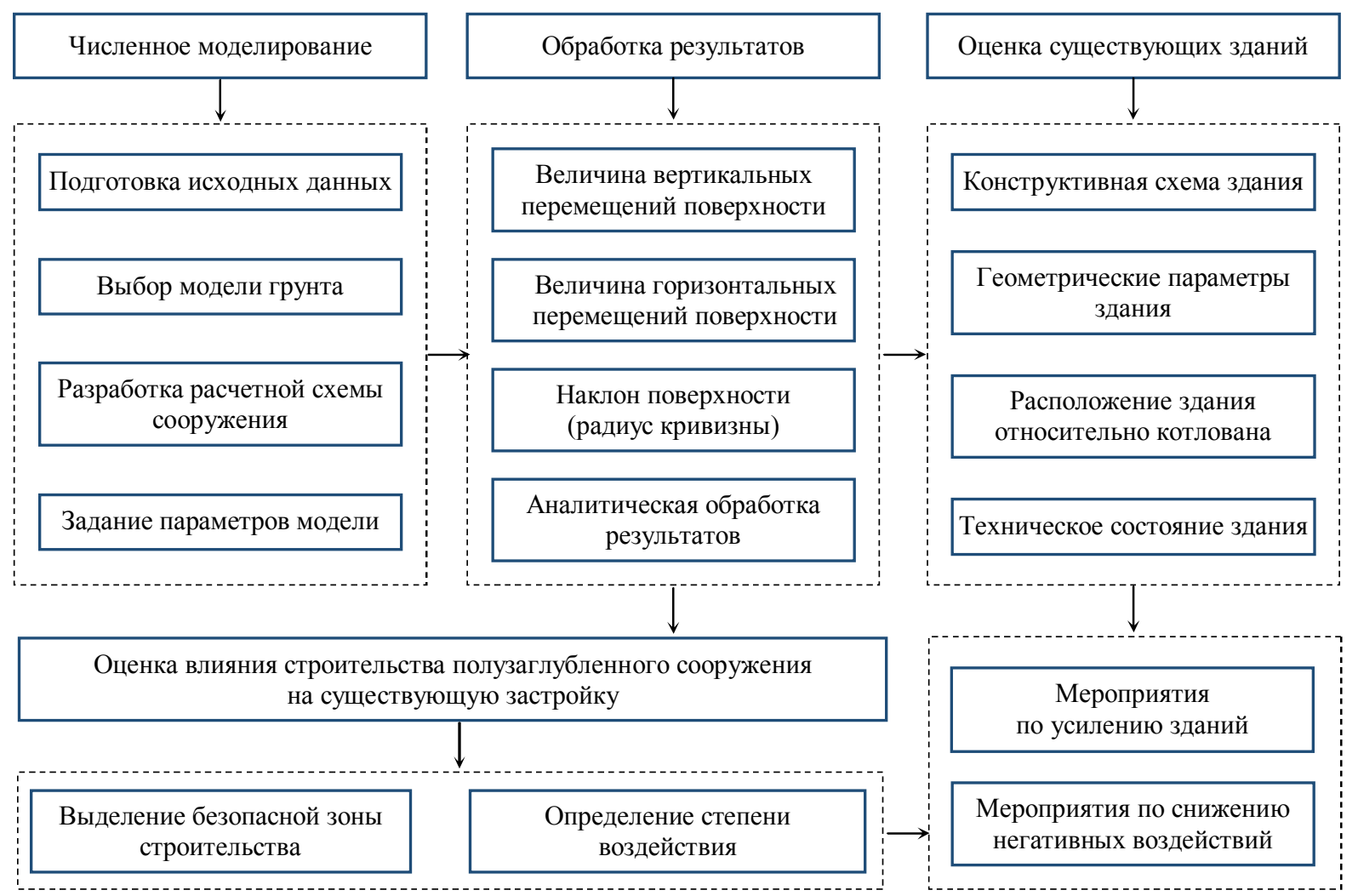

Рис.1. Алгоритм расчета полузаглубленных подземных сооружений

Сегодня существует большое количество моделей поведения грунта. Они отличаются как сложностью, объемом входных данных, так и областью применения к конкретным грунтам. Выбранная модель грунта должна соответствовать реальному поведению грунта. Для песчаных и глинистых грунтов наиболее точные результаты показала модель упрочняющегося грунта (Hardening soil model).

Разработка расчетной схемы подразумевает задание жесткостных характеристик несущих конструкций, узлов их сопряжения и определение этапности возведения сооружения. При этом особое внимание следует уделять осушению котлована, так как оно способно существенно менять физико-механические свойства грунтов.

По результатам численного моделирования выполняется их аналитическая обработка. Проводится аппроксимация полученных зависимостей оседаний, горизонтальных перемещений поверхности, изгибающих моментов и перерезывающих сил в несущих конструкциях и т.д. при изменении характеристик вмещающих грунтов или элементов крепления. Полученные формулы могут использоваться для оперативного инженерного расчета котлованов, а также при возникновении нештатных ситуаций, что повышает безопасность строительства.

Все здания, попадающие в зону влияния строительства котлована, должны обследоваться на предмет оценки технического состояния. Составляется таблица обследуемых зданий и сооружений с указанием категорий технического состояния, их особеностями и рекомендациями по усилению (ГОСТ 31937-2011. Здания и сооружения. Правила обследования и мониторинга технического состояния).

Степень воздействия на окружающую застройку зависит от расстояния до здания или сооружения, наклона и радиуса кривизны поверхности и определяется мульдой оседания. При выделении безопасной зоны строительства необходимо учитывать особенности зданий и сооружений существующей застройки.

Самими опасными для зданий и сооружений являются неравномерные оседания. Здания с монолитным железобетонным несущим каркасом обладают наибольшей жесткостью. Предельная относительная разница в осадках для них составляет 0,0024 , для крупнопанельных бескаркасных без 

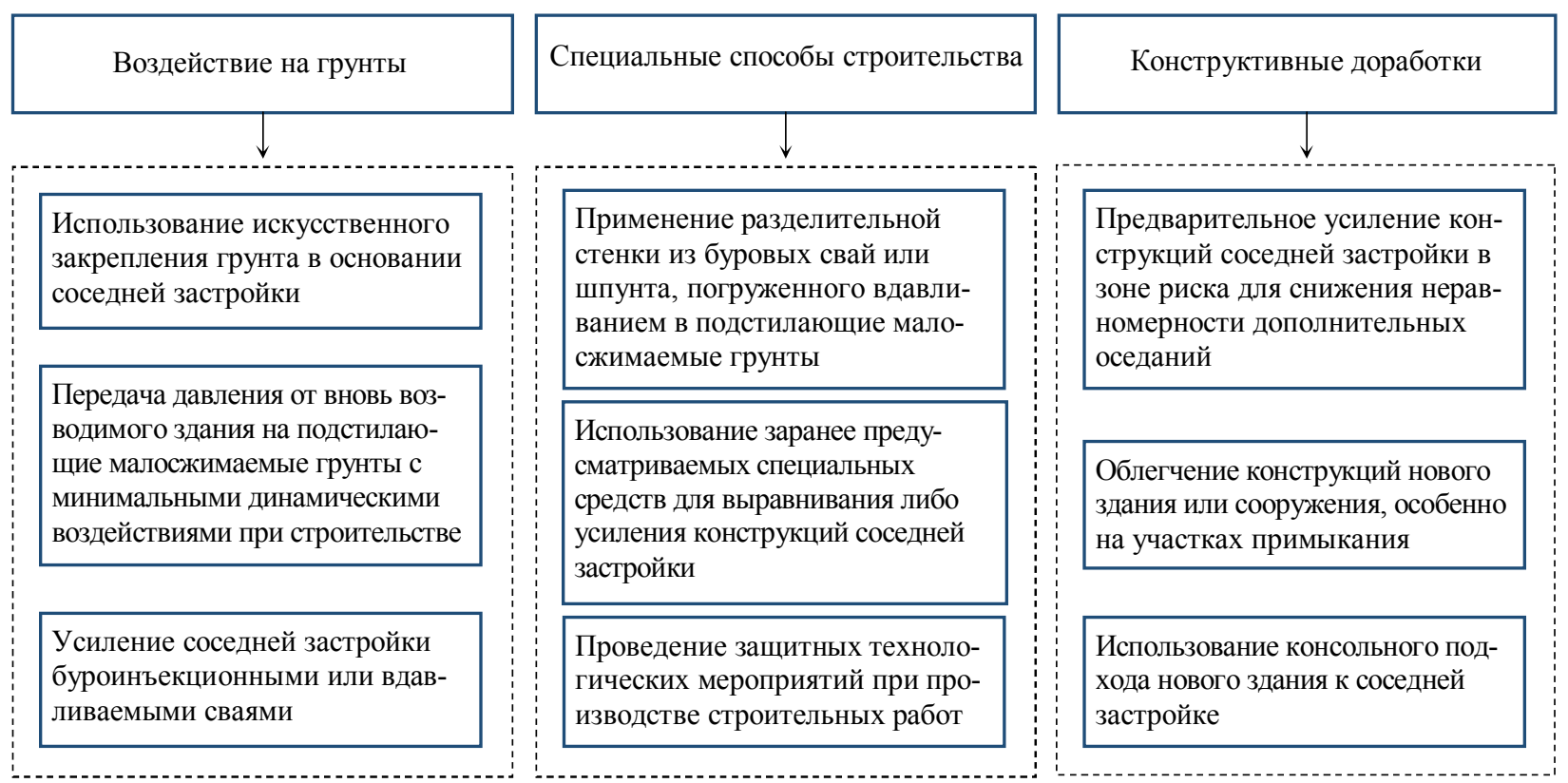

Рис.2. Классификация мероприятий, направленных на снижение негативных воздействий от строительства на соседнюю застройку

непрерывных арматурных поясов - 0,0015 (ТСН 50-302-2004. Проектирование фундаментов зданий и сооружений в Санкт-Петербурге). Коробчатые фундаменты обеспечивают наибольшую жесткость зданий и имеют самые большие предельные оседания (20-30 см) по сравнению с другими типами фундаментов.

Ширина, длина и высота являются основными геометрическими параметрами здания и по величине их отношений можно судить об устойчивости зданий. Здесь выделяются два основных типа: протяженные здания и здания башенного типа. В протяженных зданиях предельные оседания меньше, но допускается бо́льший крен по сравнению со зданиями башенного типа.

Здание по отношению к котловану может быть ориентировано под разным углом относительно бо́льшей оси здания. Предпочтительно перпендикулярное или параллельное расположение здания. Величина оседаний также напрямую зависит от расстояния до котлована.

Если совместные деформации оснований и конструкций соседней застройки превышают допустимые пределы, то проводят различные мероприятия, направленные на улучшение характеристик грунта и повышение жесткости здания или его приспособление к неравномерным воздействиям (рис.2). Разделение по категориям выполнено условно.

Апробация метода. Были выполнены численные эксперименты в плоской и объемной постановке с использованием программного комплекса Plaxis 2D и Plaxis 3D. Рассмотрено три варианта сооружения глубокого котлована (рис.3). Каждый вариант предполагает расчет с тремя различными жесткостными показателями «стены в грунте». При моделировании в плоской постановке были приняты следующие геометрические параметры вмещающего массива: ширина 200 м, высота 40 м. Задача симметричная относительно оси центра котлована. Запрещены перемещения низа модели по оси $Y$ и бока модели по оси $X$.

Ширина котлована для плоской модели 20 м. Длина котлована в объемной постановке задачи принималась 30; 35 и 40 м. Для предотвращения горизонтальных смещений стенок котлована использовалась «стена в грунте», выполненная из бетона В40 толщиной 800; 600 и 400 мм. Для повышения ее жесткости применяется распорная система с шагом 5 м по глубине. В зависимости от глубины расположения яруса менялась жесткость распорок: 1-й ярус - EI; 2-й - 2EI; 3-й - 3EI; 4-й - 1,5EI. В качестве распорки первого яруса служила стальная труба диаметром 500 мм из стали шириной 10 мм. Уровень грунтовых вод понижался на 1 м ниже дна котлована на всех этапах вычислений.

Грунты оснований зданий и сооружений могут существенно различаться в различных регионах страны. В связи с этим при моделировании рассмотрены грунты, характеризуемые раз- 
$a$

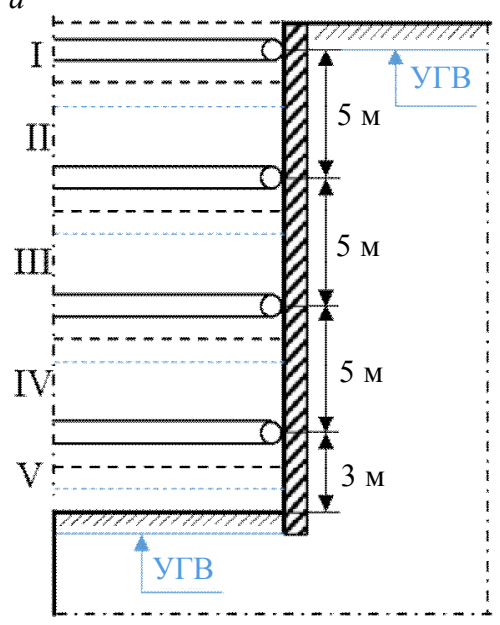

$\sigma$

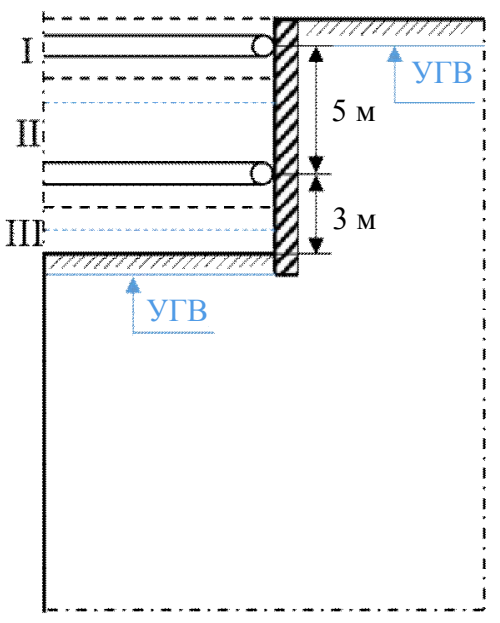

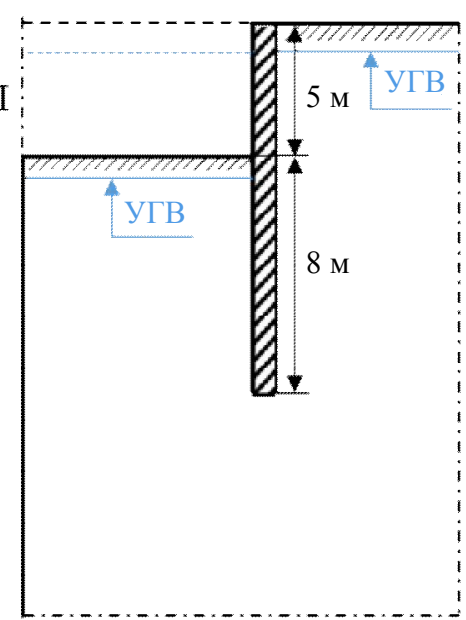

Рис.3. Варианты моделей котлована: $a-8$ - котлован глубиной 19; 9 и 5 м соответственно, консольная схема;

I-V - этапы разработки котлована

личным коэффициентом пористости $e$ : четыре варианта глинистых (модель $1-e=0,85, \ldots$, модель $4-e=0,55)$ и четыре варианта песчаных (модель $1-e=0,75, \ldots$, модель $4-e=0,45$ ). В общей сложности было выполнено около 100 расчетов.

Для расчетов была принята упруго-пластическая модель упрочняющегося грунта, учитывающая изменение свойств при малых деформациях, которая получила широкое распространение при прогнозе деформаций грунтового массива в окрестности подземных сооружений. Апробация этой геомеханической модели, проведенная отечественными и зарубежными исследователями, показала, что представленная геомеханическая модель дает более точные результаты при выполнении прогноза формирования напряженно-деформированного состояния в системе «полузаглубленное подземное сооружение - существующая застройка». Расчет велся на недренированное состояние грунтов с учетом естественной скорости фильтрации и распределения порового давления.

Основные результаты моделирования в плоской постановке для глинистых грунтов с коэффициентом пористости представлены на рис.4.

Из графиков видно, что зона влияния строительства глубокого котлована достигает 60-65 м для всех моделей. При этом максимальная величина оседаний поверхности и кривизна мульды сдвижения значительно отличаются для разных вариантов расчета. Таким образом, можно сделать вывод, что степень воздействия строительства на здания, попадающие в зону влияния для разных вариантов моделей, будет отличаться.
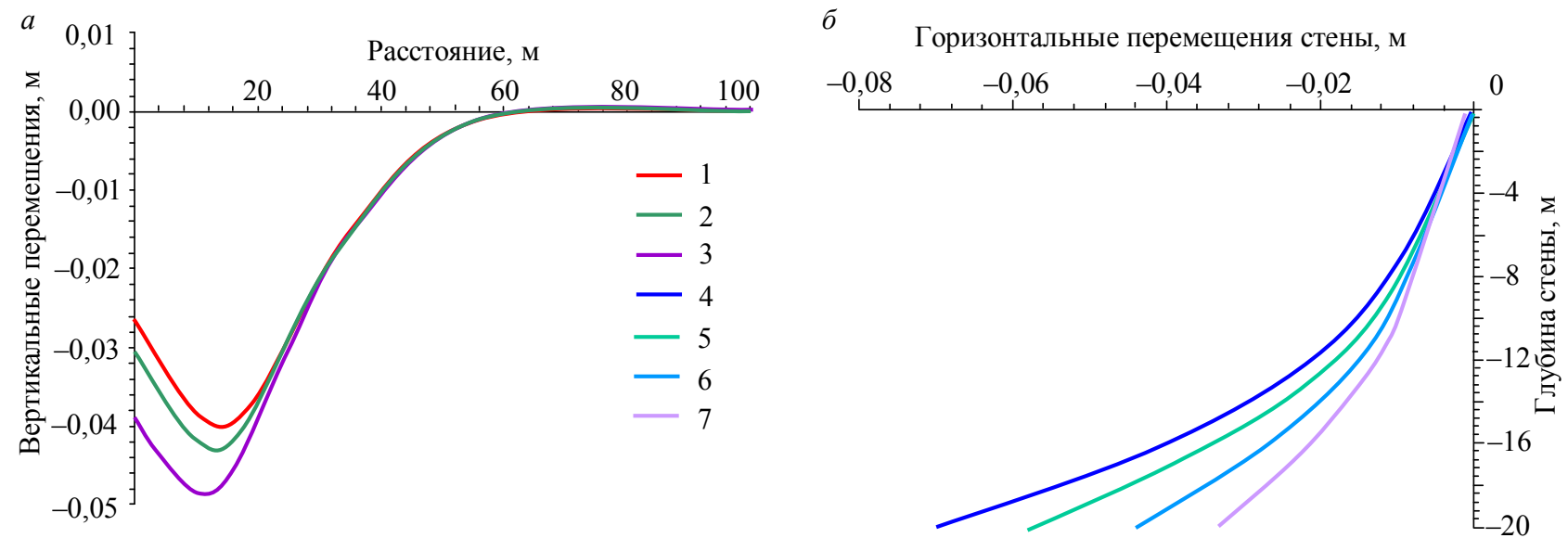

Рис.4. Графики вертикальных $(a)$ перемещений поверхности в глине № 1 с различными толщинами «стены в грунте» (модель 1) и эпюры горизонтальных смещений «стены в грунте» (б) с различными характеристиками глин (модели 1-4) Кривые 1, 4-7 - толщина стены 800 мм; 2 - 600 мм; 3 - 400 мм; $1-4-e=0,85 ; 5-0,75 ; 6-0,65 ; 7-0,55$ 


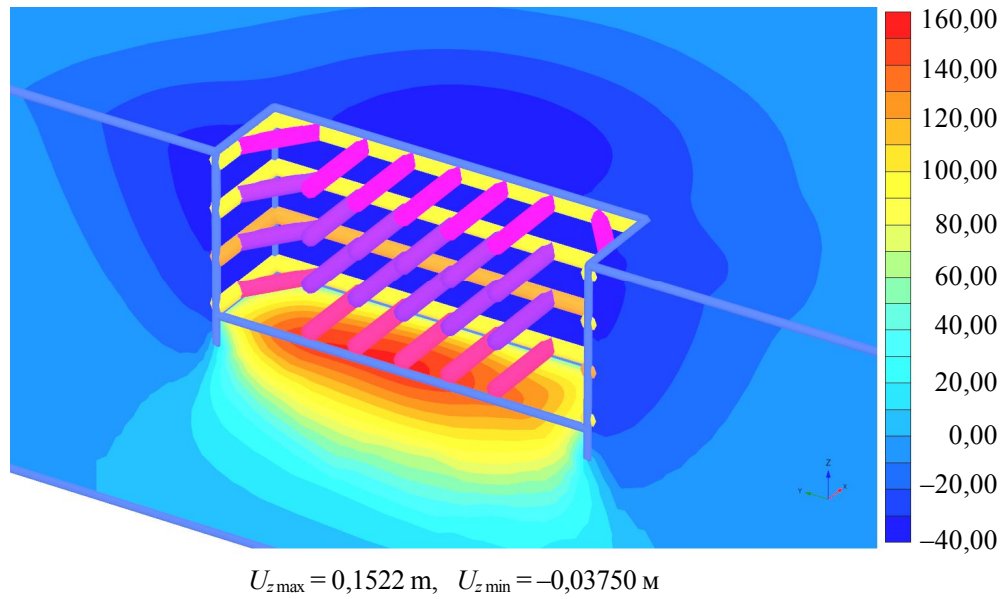

Рис.5. Мульды сдвижений земной поверхности при строительстве котлована длиной 40 м в песчаных грунтах (Plaxis 3D)

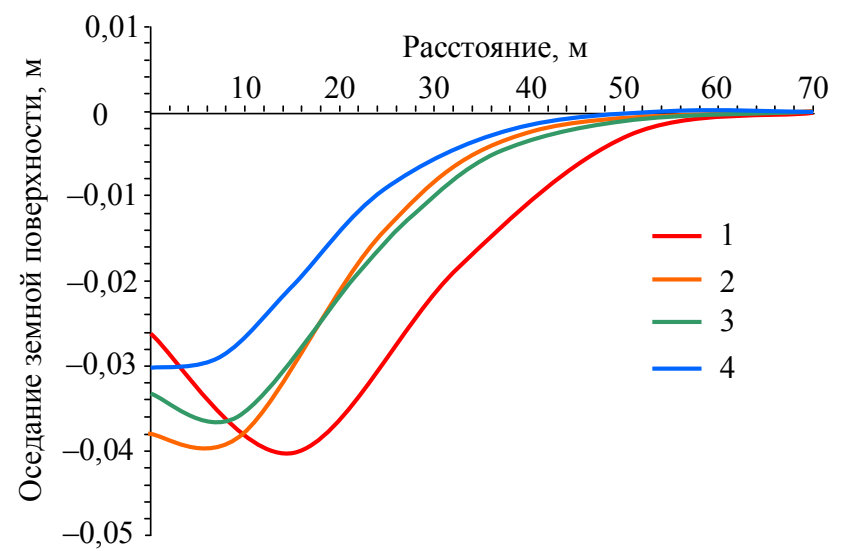

Рис.6. Графики вертикальных перемещений поверхности (толщина стены 800 мм) в глине № 1 для плоской модели (1) и 3D-моделей с различной длиной котлована $(2-4-\mathrm{B}=35 ; 30$ и 40 м соответственно) 60,00

40,00 20,00 80,00 60,00 0,00 0,00 0,00 0,00 0

$\left[\cdot 10^{-3} \mathrm{M}\right]$

загл средственной близости от существующей застройки в нашем случае требуется повысить жесткость ограждающей конструкции за счет усиления распорной системы.

Для оценки расхождения результатов моделирования в плоской и объемной постановке задачи были выполнены численные эксперименты в Plaxis 3D. Рассмотрены варианты с шириной котлована $20 \mathrm{M}$ и различной длиной $30 ; 35 ; 40$ м. Все параметры грунтового массива и конструкций задавались аналогично плоским моделям.

Оседания земной поверхности при строительстве котлована длиной 40 м в песчаных грунтах показаны на рис.5.

Кривые вертикальных перемещений поверхности при моделировании в плоской и объемной постановке задачи имеют некоторые различия (рис.6). Максимальная величина оседаний в плоской постановке (4 см) соответствует 3D-модели с длиной котлована 35 м. При этом экстремум в первом случае находится на расстоянии 15 м от стены, а во втором - 8 м. Для других длин котлована моделирование в плоской постановке дает завышенные значения по максимальной величине вертикальных перемещений поверхности. Большое оседание поверхности по графику в объемной модели с длиной котлована 35 м по сравнению с котлованом 40 м связано с расстановкой распорок. Графики строились в разрезе по центру котлована и в моделях 30 и 40 м он попал на распорки, а в модели 35 м - между распорками.

Обсуждения. Большой интерес представляет анализ наблюдений за деформациями грунтового массива в окрестности подземного сооружения, расположенного в слабых грунтах $\left(c_{u}<75\right.$ кПа), выполненных Мурманом [10]. Анализ результатов более чем 500 наблюдений показал, что в зависимости от объекта строительства горизонтальные смещения стены изменяются от $0,5 \% H\left(H-\right.$ глубина котлована) до $1,0 \% H_{e}$. Среднее значение горизонтальных смещений $0,87 \% H$. Максимумы горизонтальных смещений располагаются на расстоянии от 0,5 до $1,0 H$ от поверхности земли. Максимальные величины вертикальных смещений земной поверхности находятся в диапазоне от 0,1 до $10 \% H$. Среднее значение максимальных вертикальных смещений земной поверхности $1,1 \% \mathrm{H}$. Максимальное значение вертикальных смещений земной поверхности наблюдается на расстоянии до $0,5 \%$, однако отмечены случаи, когда значение максимальных оседаний земной поверхности удалено на расстояние до $2 \% \mathrm{H}$. 
Полученные в работе результаты хорошо согласуются с результатами других исследователей. Горизонтальные смещения стены в отношении к глубине котлована для первой и второй схем расчета не превысили $0,53 \% H$. Максимальная величина оседаний земной поверхности для первой схемы составила $0,26 \% H$, для второй $-0,18 \% H$. Консольная схема для данных условий показала большие значения перемещений. Горизонтальные перемещения стены в отношении к глубине котлована для консольной схемы достигли $2,8 \% \mathrm{H}$. Максимальная величина оседаний земной поверхности для третьей схемы $1,8 \%$. При этом для глинистых грунтов был обеспечен коэффициент запаса устойчивости не менее 1,3. В песчаных грунтах с консольной схемой и принятыми параметрами стены, а также при значительном увеличении толщины и глубины стены обеспечить устойчивость не удалось.

Заключение. Предложенный метод прогноза деформации земной поверхности при устройстве котлованов в условиях плотной городской застройки с применением способа «стена в грунте» позволяет получить полную картину взаимодействия строящегося полузаглубленного сооружения с окружающей застройкой.

Устойчивость полузаглубленного сооружения и деформации грунтового массива в его окрестности взаимосвязаны: чем выше коэффициент устойчивости, тем менее значительные деформации развиваются в грунтовом массиве. По мере снижения коэффициента запаса по устойчивости стен полузаглубленного сооружения деформации в грунтовом массиве нарастают вплоть до неконтролируемой величины. Это наблюдалось в консольной схеме ограждающих конструкций для песчаных грунтов. Расчетная схема с консольной стеной может быть успешно реализована только при небольшой глубине котлована. Максимальное оседание для котлована с толщиной стены 800 мм составило 91 мм. Горизонтальные смещения поверхности достигли 132 мм.

Применение даже наиболее надежных технологий создания ограждающих конструкций типа «стена в грунте» не позволяет полностью исключить влияние на существующую застройку. Так, максимальное оседание для глубины котлована 19 м достигало 59 мм. Зона влияния строительства распространялась до 60 м $(3 H)$.

Решения в плоской постановке дают завышенные значения зоны влияния по сравнению с трехмерной. Наблюдается почти двукратное расхождение в оседаниях по величине между плоским и объемным решением на расстоянии от стены котлована 22-55 м. Вблизи здания расхождение меньше.

В рамках статьи апробация метода была представлена только частично без детального анализа результатов и оценки влияния на здания.

Благодарность. Исследования выполнены по гранту Российского научного фонда (проект № 16-17-00117).

\section{ЛИТЕРАТУРА}

1. Деменков П.А. Прогноз безопасной зоны влияния строительства полузаглубленных подземных сооружений на окружающую среду / П.А.Деменков, Н.А.Беляков, В.И.Очкуров // Известия Тульского государственного университета. Науки о Земле. 2017. Вып. 4. С.311-324.

2. Протосеня А.Г. Изучение прочности на сжатие трещиноватого горного массива / А.Г.Протосеня, П.Э.Вербило // Записки Горного института. 2017. Т. 223. С. 51-57. DOI: 10.18454/PMI.2017.1.51

3. Протосеня А.Г. Разработка численной модели прогноза деформаций грунтового массива при строительстве полузаглубленного сооружения в программном комплексе ABAQUS / А.Г.Протосеня, М.А.Карасев // Основания, фундаменты и механика грунтов. 2014. № 2. С. 2-6.

4. Artola J. A solution to the braced excavation collapse in Singapore // M.Eng. Thesis. 2005. P. 1-86.

5. Clough G.W. Cunstruction-induced meovements of in-situ walls / G.W.Clough, T.D.O'Rourke // Design and performance of earth retaining structures. ASCE special publication. 1990. № 25. P.439-470.

6. Demenkov P.A. Predicting land-surface deformations during the construction of underground facilities of complex spatial configuration / P.A.Demenkov, M.A.Karasev, D.N.Petrov // International Journal of Civil Engineering and Technology. 2017. Vol. 8. Iss. 11. P. 1161-1171.

7. Demenkov P.A. Emergency Assessment of Semi-Embedded Construction / P.A.Demenkov, N.A.Belakov, V.I.Ochkurov // International Journal of Applied Engineering Research. 2016. Vol. 11. № 21. P. 10698-10707

8. Karlsrud K. Design of deep excavations in soft clays / K.Karlsrud, L.Andresen // Proc. of the 14-th European Conference on SMGE. Madrid. 2007. Vol. 1. P.75-99. 
Метод прогноза деформации земной поверхности...

9. Lim P.C. A Floating-Type braced excavation in soft marine clay / P.C.Lim, T.S.Tan // Proc. of Underground Singapore. November, 2003. P. 326-337.

10. Moormann C. Analysis of wall and ground movements due to deep excavations in soft soil based on a new worldwide database // Soils Found. 2004. № 44(1). P. 87-98.

11. Peck R.B. Deep excavation and tunneling in soft ground // Proceedings of the $7^{\text {th }}$ international conference on soil mechanics and foundation engineering. Mexico City. State of the art Volume. 1969. P. 225-290.

12. Protosenya A.G. Investigating mechanical properties of argillaceous grounds in order to improve safety of development of megalopolis underground space / A.G.Protosenya, M.A.Karasev, D.N.Petrov // International Journal of Applied Engineering Research. Research India Publications. 2016. Vol. 11. Iss. 16. P. 8949-8956.

13. Shirlaw J.N. Deep excavations in Singapore marine clay/ J.N.Shirlaw, T.S.Tan, K.S.Wong // Geotechnical Aspects of Underground Construction in Soft Ground: Proc. of the 5-th Int. Symposium, Amsterdam, 2005. P. 13-28.

Авторы: П.А.Деменков, д-р техн. наук, профессор, demenkov_pa@pers.spmi.ru (Санкт-Петербургский горный университет, Санкт-Петербург, Россия), Л.А.Голдобина, д-р техн. наук, профессор, goldobina la@pers.spmi.ru (Санкт-Петербургский горный университет, Санкт-Петербург, Россия), О.В.Трушко, канд. техн. наук, доцент, trushko_ov@pers.spmi.ru (СанктПетербургский горный университет, Санкт-Петербург, Россия).

Статья поступила в редакциюю 23.01.2018.

Статья принята к публикации 01.09.2018. 